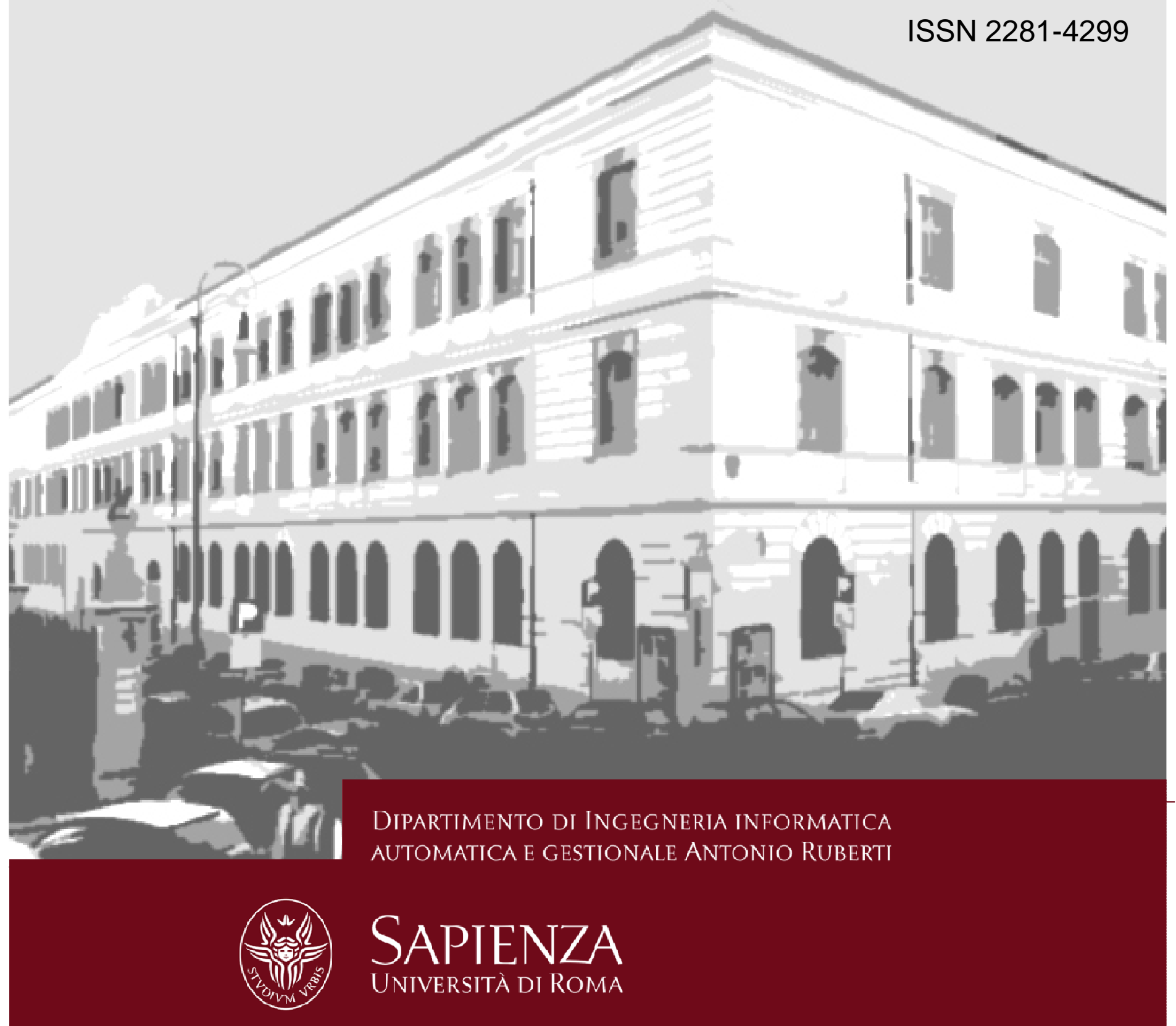

Parallel trade, product quality, and welfare

Giorgio Matteucci

Pierfrancesco Reverberi

Technical Report n. 14, 2013 


\title{
Parallel trade, product quality, and welfare
}

\author{
Giorgio Matteucci, Pierfrancesco Reverberi* \\ Dipartimento di Ingegneria informatica automatica e gestionale Antonio Ruberti \\ Sapienza - Università di Roma \\ Via Ariosto, 25 - 00185 Roma, Italia
}

\begin{abstract}
We study the welfare effects of parallel trade (PT) considering investment in quality. We thus revisit the case for allowing PT in research-intensive industries. We find that quality may be higher with than without PT, depending on how consumers' preferences for quality differ across countries. Conditional on quality, consumer surplus may rise in the source country, or fall in the destination country of PT. We find that PT reduces ex post welfare, and improving quality is a necessary (and sometimes sufficient) condition for PT to increase welfare ex ante.
\end{abstract}

Keywords: Parallel trade; Price discrimination; R\&D investment; Intellectual property rights

* Corresponding author. Phone: +39-06-77274096; fax: +39-06-77274074; e-mail: reverberi@ dis.uniroma1.it. 


\section{Introduction}

Parallel trade (PT) refers to the purchase of patented or trademarked products in one country, and the subsequent export of those products to another country, without the consent of the intellectual property rights (IPR) owner. ${ }^{1}$

The question whether PT should be permitted or banned has received growing attention in the public debate and in the academic literature. This policy issue is particularly relevant in researchintensive industries, such as pharmaceuticals. It is widely held that PT entails a trade-off between static and dynamic efficiency: the supposed positive ex post (i.e. when R\&D investment is sunk) welfare effects of allowing free circulation of goods should be weighed against the alleged negative $e x$ ante impact on investment incentives.

In this paper, we revisit the impact of PT on product quality, and thereby on consumer and social welfare. We consider a vertical pricing model of PT with endogenous quality choice where the IPR owner sells directly at home, and abroad through an independent firm.

While most theoretical models assume that the mere threat of PT leads to global uniform pricing, our model exhibits both parallel imports and third-degree retail price discrimination at equilibrium (even with no arbitrage cost). Indeed, there is evidence that PT has gained large market shares but has not yet resulted in price convergence across relevant countries. ${ }^{2}$

We find some results that run counter to the prevailing wisdom. First, product quality may be higher with than without PT, depending on how consumers' preferences for quality differ across countries. Second, with endogenous quality consumer surplus may rise in the source country, or fall in the destination country of PT. Third, PT reduces ex post global welfare. We show that improving quality is a necessary condition for PT to increase welfare ex ante (we provide a sufficient condition in an example with linear demand and quadratic R\&D cost).

\footnotetext{
${ }^{1}$ The exercise of PT hinges on the territorial exhaustion of IPR. The European Union (EU) has adopted a regime of regional exhaustion where IPR are ended upon first sale in Member States, thereby allowing free trade among them, but still hold outside the region. United States have chosen national exhaustion, where IPR owners may prevent imports. Developing countries have chosen international exhaustion, with complete trade liberalization.

${ }^{2}$ For the case of pharmaceuticals in the EU, see e.g. EFPIA-European Federation of Pharmaceutical Industries and Associations, The pharmaceutical industry in figures, 2013, available at: http://www.efpia.eu.
} 
Much of the literature agrees that PT has positive ex post welfare effects when all markets are served (Malueg and Schwartz, 1994), but leads to lower investment ex ante (Li and Maskus, 2006; Alexandrov and Deb, 2012). Valletti (2006) finds that investment in quality can be higher under international exhaustion when differential pricing between countries is cost-based rather than demandbased. Nonetheless, higher investment under international exhaustion never yields higher global welfare. In a regulated setting, Grossman and Lai (2008) find that international exhaustion may boost innovation and local consumer surplus.

The paper is organized as follows. Section 2 presents the model. Section 3 assesses quality under PT. Section 4 analyzes welfare. Section 5 discusses an example. Section 6 concludes.

\section{The model}

We set up a two-country model where a manufacturer (firm $M$ ) sells a product in country 1 through a controlled subsidiary, and in country 2 through an independent distributor (firm $D$ ). The latter may parallel export the product to country 1 at no cost (qualitative results hold if the arbitrage cost is sufficiently low: see footnote 7). Retailing costs are normalized to zero.

We consider a three-stage game. At stage one, firm $M$ carries out $\mathrm{R} \& \mathrm{D}$ and sets product quality $x>0$ at cost $C(x)$, where $C^{\prime}(x)>0$ and $C^{\prime \prime}(x)>0$. At stage two, firm $M$ manufactures the product (without loss of generality, marginal costs are normalized to zero) and sets the unit wholesale price $w$ to firm $D$. At stage three, firm $D$ sets the retail quantity (or price) in country 2 . In country 1 , should PT take place, firms compete in quantities. ${ }^{3}$

Consumers in the two countries differ in their willingness to pay (wtp) for the product and in their marginal valuation of quality, because of cross-country differences in income and/or product needs. Let $U_{j}(z, x)=z+v_{j}(x)$ be the utility of a consumer of type $z$ that buys a product of quality $x$ in country $j(j=1,2)$. We assume that $z$ is uniformly distributed between $-\infty$ and $\alpha_{j}>0$, thus avoiding

\footnotetext{
${ }^{3}$ An alternative timing where firm $M$ simultaneously sets $x$ and $w$ would not alter the equilibrium of the game. Following Maskus and Chen (2004), the assumption of Cournot competition in the destination country of PT has become standard practice in vertical pricing models of international arbitrage.
} 
that all types buy. Consumers in country $j$ are homogeneous in their preference for quality $v_{j}(x)>0 .{ }^{4}$ We assume that $v_{j}{ }^{\prime}(x)>0 .{ }^{5}$ For convenience we will sometimes use primes to denote derivatives of functions with respect to (wrt) their arguments.

A consumer of type $z$ in country $j(j=1,2)$ buys the product at price $p_{j}$ if $z+v_{j}(x)-p_{j} \geq 0$ (if the net utility is negative, $z$ will not buy). Hence, types for which $z \geq p_{j}-v_{j}(x)$ enter the market. Given their uniform distribution, there are $\alpha_{j}-\left(p_{j}-v_{j}(x)\right)$ active consumers and thus $Q_{j}=\alpha_{j}+$ $v_{j}(x)-p_{j}$ is the total quantity sold in country $j$. Let $a_{j}(x)=\alpha_{j}+v_{j}(x)$ (note that $a_{j}^{\prime}(x)>0$ ). Then, $p_{j}=a_{j}(x)-Q_{j}$ is the inverse demand curve in country $j$. In country 1 , when PT takes place we have $Q_{1}=q_{1}+q_{t}$, where $q_{1}$ is the quantity sold by firm $M$ and $q_{t}$ are parallel imports. In country 2, the monopolist firm $D$ sells $Q_{2}=q_{2}$.

We avoid corner solutions where PT is deterred or blocked, or market 2 is closed with PT. For this purpose, we assume that demand dispersion between countries is not too high, in the sense that consumers' maximum wtp in country 1 is not too much higher than in country 2 .

Assumption 1. Let $a_{1}(x)$ and $a_{2}(x)$ be such that $\frac{10}{29}<\frac{a_{2}(x)}{a_{1}(x)}<1$.

Table 1 reports firms' profit functions, consumer surplus in each country and global welfare under national exhaustion (regime $n$ ) and international exhaustion (regime $i$ ) of IPR.

\begin{tabular}{|c|c|}
\hline regime $n$ & regime $i$ \\
\hline$\pi_{M}^{n}=p_{1} q_{1}+w q_{2}-C(x)$ & $\pi_{M}^{i}=p_{1} q_{1}+w\left(q_{2}+q_{t}\right)-C(x)$ \\
$\pi_{D}^{n}=\left(p_{2}-w\right) q_{2}$ & $\pi_{D}^{i}=\left(p_{1}-w\right) q_{t}+\left(p_{2}-w\right) q_{2}$ \\
$S^{n}=S_{1}^{n}+S_{2}^{n}=q_{1}{ }^{2} / 2+q_{2}{ }^{2} / 2$ & $S^{i}=S_{1}^{i}+S_{2}^{i}=\left(q_{1}+q_{t}\right)^{2} / 2+q_{2}{ }^{2} / 2$ \\
$W^{n}=S_{1}^{n}+S_{2}^{n}+\pi_{M}^{n}+\pi_{D}^{n}$ & $W^{i}=S_{1}^{i}+S_{2}^{i}+\pi_{M}^{i}+\pi_{D}^{i}$ \\
\hline
\end{tabular}

Table 1. Firms' profit functions, consumer surplus and global welfare in both regimes.

\footnotetext{
${ }^{4}$ If instead the marginal consumer values quality less than the average consumer, then product quality would decline at equilibrium, ceteris paribus.

${ }^{5}$ We borrow the demand structure from Katz and Shapiro (1985) and several others. Qualitative results hold for more general demand structures insofar as an increase in $x$ implies parallel upward shifts in demands.
} 


\section{Product quality}

Let us analyze the impact of PT on investment incentives. Thus, we derive product quality under regime $n$ (section 3.1), regime $i$ (section 3.2), and compare the results (section 3.3).

\subsection{National exhaustion}

In regime $n$, firm $M$ is a monopoly in country 1 and firm $D$ a monopoly in country 2 . At stage three, the first-order condition (FOC) on each firm's profit wrt quantity gives $q_{1}^{n}(x)=\frac{a_{1}(x)}{2}, q_{2}^{n}(x, w)=$ $\frac{\left(a_{2}(x)-w\right)}{2}$. At stage two, the FOC on firm $M$ 's profit wrt the wholesale price gives $w^{n}(x)=\frac{a_{2}(x)}{2}$. Inserting for $w^{n}(x)$, the quantity sold in country 2 is $q_{2}^{n}(x)=\frac{a_{2}(x)}{4}$. At stage one, quality derives from the FOC on firm $M$ 's profit wrt $x$ (assuming an interior solution):

$\frac{\partial \pi_{M}^{n}(x)}{\partial x}=\frac{1}{4}\left(2 a_{1}(x) a_{1}^{\prime}(x)+a_{2}(x) a_{2}^{\prime}(x)\right)-C^{\prime}(x)=0$

provided that the second-order condition (SOC) holds, namely, $\frac{\partial^{2} \pi_{M}^{n}(x)}{\partial x^{2}}<0 .^{6}$

Let $x^{n}$ be the solution to (1).

\subsection{International exhaustion}

In regime $i$, at stage three firm $M$ and firm $D$ compete à la Cournot in country 1 , while firm $D$ is a monopoly in country 2 . Hence, the equilibrium quantities are:

$\left\{\begin{array}{l}q_{1}^{i}(x, w)=\frac{a_{1}(x)+w}{3} \\ q_{t}(x, w)=\frac{a_{1}(x)-2 w}{3} \\ q_{2}^{i}(x, w)=\frac{a_{2}(x)-w}{2}\end{array}\right.$

Let $w^{i}(x)$ be the price that derives from the FOC on firm M's profit at stage two:

$w^{i}(x)=w^{n}(x)+w_{t}(x)=\frac{a_{2}(x)}{2}+\frac{5}{19}\left(a_{1}(x)-a_{2}(x)\right)>w^{n}(x)$.

From Assumption 1, for a given quality firm $M$ raises the wholesale price relative to regime $n$ to effectively control PT. ${ }^{7}$ Since $\partial w^{i}(x) / \partial x>0$, then the wholesale price rises with quality.

\footnotetext{
${ }^{6}$ At stages two and three, the SOCs are always fulfilled in both regimes.
} 
Inserting $w^{i}(x)$ into (2), we find that:

$$
\begin{aligned}
& q_{1}^{i}(x)=\frac{1}{38}\left(16 a_{1}(x)+3 a_{2}(x)\right) \\
& q_{t}(x)=\frac{3}{19}\left(a_{1}(x)-a_{2}(x)\right) \\
& q_{2}^{i}(x)=\frac{1}{76}\left(29 a_{2}(x)-10 a_{1}(x)\right)
\end{aligned}
$$

Given (5) and (6), Assumption 1 ensures that $q_{t}(x)>0$ and $q_{2}^{i}(x)>0$.

From (5), we have $\frac{\partial q_{t}(x)}{\partial x}=\frac{3\left(a_{1}{ }^{\prime}(x)-a_{2}{ }^{\prime}(x)\right)}{19}$. Thus, parallel imports may rise or fall with quality depending on whether the marginal valuation of quality is respectively higher or lower in country 1 than in country 2. Given that $\left.\frac{\partial \pi_{M}^{i}(x)}{\partial q_{t}(x)}\right|_{w=w^{i}(x)}=-q_{t}(x)<0$, namely, parallel imports reduce firm $M$ 's profit, when $a_{2}{ }^{\prime}(x)>a_{1}{ }^{\prime}(x)$ firm $M$ may strategically raise investment in quality to effectively control PT.

At stage one, product quality derives from the FOC on firm $M$ 's profit wrt $x$ (assuming an interior solution):

$\frac{\partial \pi_{M}^{i}(x)}{\partial x}=\frac{1}{76}\left(2\left(14 a_{1}(x)+5 a_{2}(x)\right) a_{1}{ }^{\prime}(x)+\left(10 a_{1}(x)+9 a_{2}(x)\right) a_{2}{ }^{\prime}(x)\right)-C^{\prime}(x)=0$

provided that the SOC is fulfilled, namely, $\frac{\partial^{2} \pi_{M}^{i}(x)}{\partial x^{2}}<0$. Let $x^{i}$ be the solution to (7).

\subsection{Comparison}

We find that PT per se does not reduce investment. ${ }^{8}$ Proposition 1 shows that a necessary and sufficient condition for PT to increase investment (and thereby product quality) is that consumers in country 2 have a higher marginal wtp for quality than consumers in country 1 .

\footnotetext{
${ }^{7}$ We can find that Assumption 1 excludes that $w^{i}(x) \geq \frac{a_{1}(x)}{2}$ and, from (2), PT is deterred. Since $a_{1}(x)>$ $a_{2}(x)$, then $\frac{a_{1}(x)}{2}>w^{i}(x)>\frac{a_{2}(x)}{2}=w^{n}(x)$. This rules out the naïve case where PT is blocked, namely, where PT does not occur even if firm $M$ chooses $\left(w^{n}, x^{n}\right)$ and thus behaves in regime $i$ as in regime $n$. We assume away any arbitrage cost $s$. As long as $0 \leq s<\frac{3}{10}\left(a_{1}(x)-a_{2}(x)\right)$ there is an interior equilibrium with PT, and our qualitative results still hold. For higher values of $s$, firm $M$ would deter PT at equilibrium.

${ }^{8}$ For product quality in regimes $i$ and $n$ to be suitably compared, the relevant SOCs must simultaneously hold, namely, the cost function must be sufficiently convex.
} 
Proposition 1. Product quality is higher with than without PT when consumers' marginal valuation of quality is higher in country 2 than in country 1.

Proof of Proposition 1. From $\frac{\partial^{2} \pi_{M}^{k}(x)}{\partial x^{2}}<0$ we have $\frac{\partial \pi_{M}^{k}(x)}{\partial x}>0$ for $0<x<x^{k} \quad(k=i, n)$, and $\frac{\partial \pi_{M}^{n}\left(x^{n}\right)}{\partial x}=0 . \quad$ We $\quad$ can find that: $\frac{\partial \pi_{M}^{i}(x)}{\partial x}-\frac{\partial \pi_{M}^{n}(x)}{\partial x}=\frac{5\left(a_{2}{ }^{\prime}(x)-a_{1}{ }^{\prime}(x)\right)}{38}\left(a_{1}(x)-a_{2}(x)\right)$. From Assumption $1, a_{1}(x)-a_{2}(x)>0$. Hence, $\frac{\partial \pi_{M}^{i}(x)}{\partial x}-\frac{\partial \pi_{M}^{n}(x)}{\partial x}>0$ when $a_{2}{ }^{\prime}(x)>a_{1}{ }^{\prime}(x)$. Let $a_{2}{ }^{\prime}(x)>$ $a_{1}^{\prime}(x)$. Since $\frac{\partial \pi_{M}^{i}\left(x^{n}\right)}{\partial x}-\frac{\partial \pi_{M}^{n}\left(x^{n}\right)}{\partial x}=\frac{\partial \pi_{M}^{i}\left(x^{n}\right)}{\partial x}>0$, then we have $x^{i}>x^{n}$.

\section{Welfare analysis}

Consider now how PT affects consumer surplus (section 4.1) and social welfare (section 4.2).

\subsection{Consumer surplus}

We show that total ex post consumer surplus is higher with than without PT. For any given quality, PT raises (respectively, reduces) the quantity sold in country 1 (country 2). Thus, PT raises consumer surplus in the destination country but reduces surplus in the source country.

Interestingly, we show that the ex ante analysis may yield opposite results. If PT raises (respectively, reduces) investment, and thereby the quantity sold, then consumer surplus in the source (destination) country of PT may be higher (lower) in regime $i$ than in regime $n$.

Proposition 2. Ex post (for any given quality) consumer surplus falls in the source country, and rises in the destination country of PT. Ex ante (considering investment) consumer surplus may rise in the source country, or fall in the destination country of PT depending on quality.

Proof of Proposition 2. At the second stage of the game, from sections 3.1 and 3.2 the effects of PT on consumer surplus in country 2 follow from having $q_{2}^{i}(x)=q_{2}^{n}(x)-\frac{w_{t}(x)}{2}<q_{2}^{n}(x)$, and in country 1 from having $Q_{1}^{i}(x)=q_{1}^{i}(x)+q_{t}(x)=q_{1}^{n}(x)+\frac{q_{t}}{2}(x)>q_{1}^{n}(x)$.

Consider now the first stage of the game. As regards country 2, from sections 3.1 and 3.2 we find that $\quad q_{2}^{i}\left(x^{i}\right)-q_{2}^{n}\left(x^{n}\right)=\left(\frac{a_{2}\left(x^{i}\right)-w^{i}\left(x^{i}\right)}{2}-\frac{a_{2}\left(x^{n}\right)-w^{n}\left(x^{n}\right)}{2}\right)=\frac{1}{2}\left(a_{2}\left(x^{i}\right)-a_{2}\left(x^{n}\right)\right)-\frac{1}{2}\left(w^{i}\left(x^{i}\right)-\right.$ 
$\left.w^{n}\left(x^{n}\right)\right)$. We also have that $w^{i}\left(x^{i}\right)=w^{n}\left(x^{i}\right)+w_{t}\left(x^{i}\right)$ and $w^{n}(x)=\frac{a_{2}(x)}{2}$. Then, we find: $w^{i}\left(x^{i}\right)-w^{n}\left(x^{n}\right)=w^{n}\left(x^{i}\right)-w^{n}\left(x^{n}\right)+w_{t}\left(x^{i}\right)=\frac{1}{2}\left(a_{2}\left(x^{i}\right)-a_{2}\left(x^{n}\right)\right)+w_{t}\left(x^{i}\right) . \quad$ Hence, $\quad$ we have: $q_{2}^{i}\left(x^{i}\right)-q_{2}^{n}\left(x^{n}\right)=\frac{1}{2}\left(\frac{1}{2}\left(a_{2}\left(x^{i}\right)-a_{2}\left(x^{n}\right)\right)-w_{t}\left(x^{i}\right)\right)$. It follows that $q_{2}^{i}\left(x^{i}\right)-q_{2}^{n}\left(x^{n}\right)>0$, and thus $S_{2}^{i}\left(x^{i}\right)>S_{2}^{n}\left(x^{n}\right)$ when $a_{2}\left(x^{i}\right)-a_{2}\left(x^{n}\right)>2 w_{t}\left(x^{i}\right)$.

As regards country 1, we have: $Q_{1}^{i}\left(x^{i}\right)=q_{1}^{i}\left(x^{i}\right)+q_{t}\left(x^{i}\right)=q_{1}^{n}\left(x^{i}\right)+\frac{1}{2} q_{t}\left(x^{i}\right)=\frac{a_{1}\left(x^{i}\right)}{2}+$ $\frac{1}{2} q_{t}\left(x^{i}\right)$. Since $q_{1}^{n}\left(x^{n}\right)=\frac{a_{1}\left(x^{n}\right)}{2}$ then we have $Q_{1}^{i}\left(x^{i}\right)-q_{1}^{n}\left(x^{n}\right)<0$, and thereby $S_{1}^{i}\left(x^{i}\right)<S_{1}^{n}\left(x^{n}\right)$ when $a_{1}\left(x^{n}\right)-a_{1}\left(x^{i}\right)>q_{t}\left(x^{i}\right)$.

In country 2 , since $a_{2}{ }^{\prime}(x)>0$ then we have $a_{2}\left(x^{i}\right)-a_{2}\left(x^{n}\right)>0$ when $x^{i}>x^{n}$. If $x^{i}$ is sufficiently higher than $x^{n}$, then we may have $a_{2}\left(x^{i}\right)-a_{2}\left(x^{n}\right)>2 w_{t}\left(x^{i}\right)>0$. In such a case, the output expansion in regime $i$ following the increase in product quality (that in turn raises consumers' wtp) more than compensates the output contraction following the increase in the wholesale price relative to regime $n$. Thus, PT increases consumer surplus in country 2.

In country 1 , since $a_{1}{ }^{\prime}(x)>0$ then we have $a_{1}\left(x^{i}\right)-a_{1}\left(x^{n}\right)>0$ when $x^{i}>x^{n}$. Hence, PT improves consumer surplus in country 1 . Conversely, $x^{n}>x^{i}$ implies $a_{1}\left(x^{n}\right)-a_{1}\left(x^{i}\right)>0$, and may then imply $a_{1}\left(x^{n}\right)-a_{1}\left(x^{i}\right)>q_{t}\left(x^{i}\right)>0$ when parallel imports are relatively small. In such a case, PT reduces consumer surplus in country 1.

In section 5, we will illustrate the above conditions in an example.

At the world level, from (3)-(6) we can find that $\Delta S(x)=S^{i}(x)-S^{n}(x)=\frac{\left(148 a_{1}(x)-129 a_{2}(x)\right)\left(a_{1}(x)-a_{2}(x)\right)}{2888}>0$ (under Assumption 1). Thus, PT raises ex post consumer surplus. We can prove that PT has ambiguous effects on the ex ante total consumer surplus.

\subsection{Social welfare}

We find that PT reduces ex post global welfare. For a given quality, the adverse effect of PT on industry profits (although firm D's profit may rise under PT, this does not offset firm $M$ 's profit loss) 
outweighs the positive effect on total consumer surplus. ${ }^{9}$ We show that, for PT to improve ex ante global welfare, quality should improve in regime $i$ relative to regime $n$.

Proposition 3. PT reduces ex post global welfare (for any given product quality). Improving product quality is a necessary condition for PT to improve global welfare ex ante.

Proof of Proposition 3. Consider first global welfare at the second stage of the game. From (3)-(6), we can find that: $\Delta \Pi(x)=\Delta \pi_{M}(x)+\Delta \pi_{D}(x)=\left(\pi_{M}^{i}(x)-\pi_{M}^{n}(x)\right)+\left(\pi_{D}^{i}(x)-\pi_{D}^{n}(x)\right)=$ $-\frac{\left(a_{1}(x)-a_{2}(x)\right)\left(34 a_{1}(x)+61 a_{2}(x)\right)}{1444}<0$ (under Assumption 1). For any $x$, computation yields that: $\Delta W(x)=W^{i}(x)-W^{n}(x)=\Delta S(x)+\Delta \Pi(x)=\frac{\left(80 a_{1}(x)-251 a_{2}(x)\right)\left(a_{1}(x)-a_{2}(x)\right)}{2888}$. Since $\quad a_{1}(x)>$ $a_{2}(x)$ (Assumption 1), then $\Delta W(x)>0$ when $0<\frac{a_{2}(x)}{a_{1}(x)}<\frac{80}{251}$. However, Assumption 1 requires that $\frac{10}{29}<\frac{a_{2}(x)}{a_{1}(x)}$ for $q_{2}^{i}(x)>0$ to hold. Since $\frac{10}{29}>\frac{80}{251}$, then we cannot have both $\Delta W(x)>0$ and $q_{2}^{i}(x)>$ 0 . Thus, $\Delta W(x)<0$ holds when $\frac{10}{29}<\frac{a_{2}(x)}{a_{1}(x)}<1$.

Consider now global welfare at the first stage. Let quality be lower with than without PT (i.e. $\left.x^{i}<x^{n}\right)$. Since $\quad \frac{\partial \pi_{M}^{n}(x)}{\partial x} \geq 0 \quad$ for $\quad 0<x \leq x^{n} \quad$ then we have $\frac{\partial W^{n}(x)}{\partial x} \geq \frac{\partial W^{n}(x)}{\partial x}-\frac{\partial \pi_{M}^{n}(x)}{\partial x}=\frac{1}{16}\left(4 a_{1}(x) a_{1}{ }^{\prime}(x)+3 a_{2}(x) a_{2}{ }^{\prime}(x)\right)>0 \quad$ for $\quad 0<x \leq x^{n} \quad$ (where $\left.\frac{\partial \pi_{M}^{n}\left(x^{n}\right)}{\partial x}=0\right)$. Since $x^{i}<x^{n}$ then $W^{n}\left(x^{i}\right)<W^{n}\left(x^{n}\right)$. We have proved that, at stage two, Assumption 1 implies $W^{i}(x)-W^{n}(x)<0$ for any $x$. Then, $W^{i}\left(x^{i}\right)-W^{n}\left(x^{i}\right)<0$ holds when $\frac{10}{29}<\frac{a_{2}\left(x^{i}\right)}{a_{1}\left(x^{i}\right)}<1$. Since $W^{n}\left(x^{i}\right)<W^{n}\left(x^{n}\right)$, then $W^{i}\left(x^{i}\right)-W^{n}\left(x^{n}\right)<W^{i}\left(x^{i}\right)-W^{n}\left(x^{i}\right)<0$ also holds when $\frac{10}{29}<\frac{a_{2}\left(x^{i}\right)}{a_{1}\left(x^{i}\right)}<1$. Thus, if $x^{i}<x^{n}\left(\right.$ and $\left.q_{2}^{i}\left(x^{i}\right)>0\right)$ then $W^{i}\left(x^{i}\right)-W^{n}\left(x^{n}\right)<0$.

\footnotetext{
${ }^{9}$ Thus, our vertical pricing model of PT reverses the standard result based on the classic theory of third-degree price discrimination that PT improves ex post welfare when demand dispersion is small enough that all countries are served under PT (Malueg and Schwartz, 1994).
} 


\section{An example}

To proceed further in the welfare analysis, we consider an example with a quadratic cost of R\&D and

a demand that is linear in quality. Thus, let $C(x)=\varphi \frac{x^{2}}{2}$, where $\varphi>0$. Let also $a_{1}(x)=a+\beta_{1} x$, and $a_{2}(x)=1+\beta_{2} x$, where $a>1$ and $\beta_{j}>0(j=1,2)$.

Our main purpose is to find a sufficient condition for ex ante global welfare to improve under PT. Proposition 3 implies that $x^{i}>x^{n}$ must hold. Thus, Proposition 1 requires that $\beta_{2}>\beta_{1}$. Let $\varphi^{*}=$ $\frac{\left(2 \beta_{1}+\beta_{2}\right)\left(a \beta_{2}-\beta_{1}\right)}{4(a-1)}$ and $\varphi^{* *}=\frac{\left(12 \beta_{1}+5 \beta_{2}\right)\left(a \beta_{2}-\beta_{1}\right)}{10 a-29}$. For Assumption 1 to hold at equilibrium, we must have $\varphi>\varphi^{*}$ when $1<a<\frac{29}{10}$, and $\varphi^{*}<\varphi<\varphi^{* *}$ when $a \geq \frac{29}{10}$.

Assume that the cost parameter $\varphi$ converges (from above) to the critical value $\varphi^{*}$. Then, Proposition 4 proves that, in a neighbourhood around $\varphi^{*}$, ex ante global welfare increases under PT when consumers' maximum wtp in country 1 is high enough.

Proposition 4. Consider a linear demand and a quadratic $R \& D$ cost function. Assume that PT improves product quality. Then, in a neighbourhood around the minimum value of the cost parameter that ensures an interior equilibrium, ex ante global welfare is higher with than without PT when demand dispersion is high enough.

Proof of Proposition 4. Let $\beta_{2}>\beta_{1}$. It follows that $x^{i}>x^{n}$, which is a necessary condition to have $\Delta W=W^{i}\left(x^{i}\right)-W^{n}\left(x^{n}\right)>0$. The FOCs on firm $M$ 's profit wrt $x$ respectively give $x^{n}=\frac{2 a \beta_{1}+\beta_{2}}{4\left(\varphi-\varphi^{n}\right)}$ in regime $n$ and $x^{i}=\frac{\left(2 a \beta_{1}+\beta_{2}\right)+10\left(\beta_{1}+3 a \beta_{1}+\beta_{2}+a \beta_{2}\right)}{76\left(\varphi-\varphi^{i}\right)}$ in regime $i$, where $\varphi^{n}=\frac{1}{4}\left(2 \beta_{1}^{2}+\beta_{2}^{2}\right)$ and $\varphi^{i}=\varphi^{n}-\frac{5}{38}\left(\beta_{1}-\beta_{2}\right)^{2}$ are the minimum values of $\varphi$ for the SOCs to hold. Since we find that $\varphi^{*}>\varphi^{n}>\varphi^{i}$, then assuming $\varphi>\varphi^{*}$ ensures that the SOCs hold in both regimes.

Computation yields that: $\Delta W=\frac{(a-1)\left(\varphi-\varphi^{*}\right) H(\varphi)}{4\left(4\left(\varphi-\varphi^{n}\right)\right)^{2}\left(76\left(\varphi-\varphi^{i}\right)\right)^{2}}$, where $(a-1)\left(\varphi-\varphi^{*}\right) H(\varphi)$ is a polynomial of fourth degree in $\varphi$. We can find that $\Delta W$ has the following properties:

(i) $\lim _{\varphi \rightarrow \varphi^{*}} \Delta W=0$; 
(ii) $\lim _{\varphi \rightarrow \varphi^{*}} \frac{\partial \Delta W}{\partial \varphi}=\underbrace{\frac{(a-1)^{2}\left(a \beta_{2}-\beta_{1}\right)}{2\left(\beta_{1}-\beta_{2}\right)^{2}\left(2 a \beta_{1}+\beta_{2}\right)\left(2(5+14 a) \beta_{1}+(9+10 a) \beta_{2}\right)}}_{>0}\left(2(a-10) \beta_{1}+3(5 a-8) \beta_{2}\right)$.

The term $\left(2(a-10) \beta_{1}+3(5 a-8) \beta_{2}\right)$ is a linear increasing function of $a$ and is positive when $a>\frac{20 \beta_{1}+24 \beta_{2}}{2 \beta_{1}+15 \beta_{2}}$ (with $\frac{20 \beta_{1}+24 \beta_{2}}{2 \beta_{1}+15 \beta_{2}}<\frac{29}{10}$ for $\beta_{2}>\beta_{1}$ ). Hence, $\lim _{\varphi \rightarrow \varphi^{*}} \frac{\partial \Delta W}{\partial \varphi}>0$ when $a>\frac{20 \beta_{1}+24 \beta_{2}}{2 \beta_{1}+15 \beta_{2}}$. Thus, there is a sufficiently small $\varepsilon>0$ such that $\Delta W>0$ if $\varphi^{*}<\varphi<\varphi^{*}+\varepsilon$.

As for consumer surplus (see Proposition 2), condition $a_{2}\left(x^{i}\right)-a_{2}\left(x^{n}\right)>2 w_{t}\left(x^{i}\right)$ that ensures $S_{2}^{i}\left(x^{i}\right)>S_{2}^{n}\left(x^{n}\right)$, becomes in this example $\beta_{2}\left(x^{i}-x^{n}\right)>w^{i}\left(x^{i}\right)-w^{n}\left(x^{n}\right) .{ }^{10}$

Figure 1 displays the ex ante differences in global welfare (left panel) and in consumer surplus in country 2 (right panel) between the two regimes as a function of $\varphi$, for a given array of parameter values. Figure 1 confirms that, when quality rises with PT (since $\beta_{2}>\beta_{1}$ ), ex ante consumer surplus may rise even in country 2 (Proposition 2). It also shows that, in a neighbourhood around $\varphi^{*}$, ex ante global welfare rises with PT (Proposition 4).
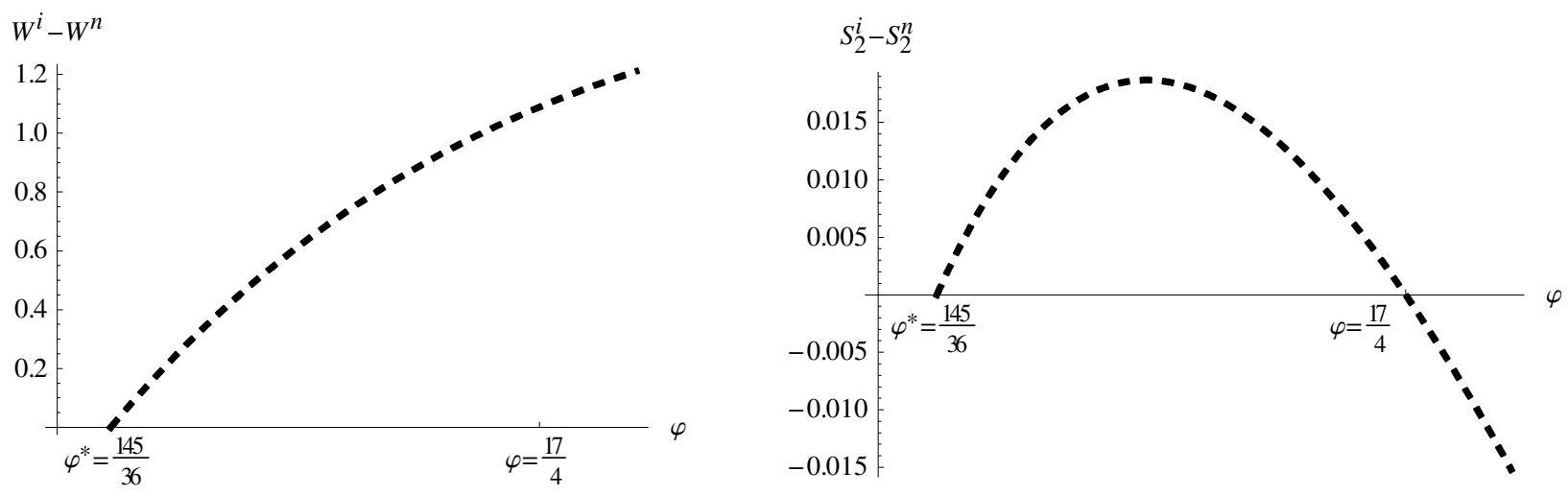

Figure 1. Ex ante welfare impact of parallel trade (Parameter values: $a=10, \beta_{1}=1, \beta_{2}=3$ ).

\section{Concluding remarks}

We have studied the welfare effects of PT considering investment in quality. We have thus revisited the case for a regime of international exhaustion of IPR in high-R\&D industries.

${ }^{10}$ Condition $a_{1}\left(x^{n}\right)-a_{1}\left(x^{i}\right)>q_{t}\left(x^{i}\right)$ that ensures $S_{1}^{i}\left(x^{i}\right)<S_{1}^{n}\left(x^{n}\right)$, becomes $x^{i}<\frac{\beta_{1} x^{n}-\frac{3}{19}(a-1)}{\beta_{1}-\frac{3}{19}\left(\beta_{2}-\beta_{1}\right)}$. We can find a set of parameter values for which this condition holds. Further details are available from the authors. 
We have found that quality is higher in an equilibrium with PT, provided that consumers' marginal valuation of quality is higher abroad than at home. In such a case, the manufacturer raises investment to effectively control PT. When quality is higher (respectively, lower) with than without PT, consumer surplus may rise (fall) in the source (destination) country of PT, thereby reversing the anticipated ex post effects of PT on consumers' well-being.

For a given quality, the adverse effect of PT on industry profits outweighs the positive effect on total consumer surplus. Thus, PT reduces ex post global welfare. Improving product quality is a necessary and sometimes sufficient condition for PT to increase welfare ex ante.

Future work may investigate whether the results are robust to considering asymmetric price regulation between countries, and a competitive market for parallel imports.

\section{References}

Alexandrov A., J. Deb (2012), "Price discrimination and investment incentives", International Journal of Industrial Organization 30: 615-623.

Grossman G.M., E.L.-C. Lai (2008), "Parallel imports and price controls", RAND Journal of Economics 39: 378-402.

Katz M., C. Shapiro (1985), "Network externalities, competition, and compatibility", American Economic Review 75: 424-440.

Li C., K.E. Maskus (2006), “The impact of parallel imports on investments in cost-reducing research and development", Journal of International Economics 68: 443-455.

Malueg D.A., M. Schwartz (1994), "Parallel imports, demand dispersion, and international price discrimination", Journal of International Economics 37: 167-195.

Maskus K., Y. Chen (2004), "Vertical price control and parallel imports: theory and evidence", Review of International Economics 12: 551-570.

Valletti T. (2006), "Differential pricing, parallel trade, and the incentive to invest", Journal of International Economics 70: 314-324. 